Rother K, Till GO, Hänsch GM (eds)

\section{The Complement System}

Springer, Berlin 1998

XX + 564 pp.; DEM 248.-

ISBN 3-540-61894-5

Complement provides an important host defence system involved in a multitude of immune reactions, including opsonisation of micro-organisms, enhancement of the inflammatory response, clearance of immune complexes and cell lysis. The first English edition of The Complement System, following an earlier German one, was published in 1987 and was well received by biochemists and immunologists working in the complement field. Through the years, it became a standard text book in many laboratories. After 11 years, it was time to publish the second edition, considering the multiple new developments in this area.

This second edition not only represents a thorough revision of the 1987 edition, but also focusses much more on biological functions (chapter 2, including the topics 'Host defence', 'Reproduction' and 'Network Interactions') and the role of complement in pathological conditions (chapter 3, including the topics 'Deficiencies', 'Transplantation' and 'Biocompatibility').

The editors and authors, all outstanding scientists in the complement field, have succeeded in providing a broad and comprehensive textbook which can be recommended to basic researchers and scientists working in medical microbiology or immunology. For clinicians, I especially recommend chapter 5 on 'The Clinical Laboratory: Testing the Complement System', which details virtually all available complement assays. However, this very impressive chapter alone does not compensate for the overall lack of clinical orienta- tion. Although clinical subjects are addressed, they are scattered from a clinical point of view, e.g. sections 2.2, 3.3 and 3.4, which are important for nephrologists. Very short structural sections on 'Complement in Dermatological Diseases' or 'Complement in Renal Diseases' could have told the clinician which chapters are important for him/her and how they are interconnected with each other without necessarily going into detail in that section.

This comprehensive book has also incorporated the newly discovered 'MBLectin Pathway', not only by introducing this system in one excellently written section, but also by referring to it throughout the book in different sections: I was also delighted to see a chapter on 'Complement Manipulation in vivo' (chapter 4). However, this chapter, although very nicely written, is a bit short considering the many new developments in this field, e.g. complement inhibitory antibodies and the preliminary use of complement regulators in xenotransplantation, which could have been mentioned there as well.

Unfortunately, the previous chapter on 'Complement Genetics' was completely omitted from the second edition, without even referring to this topic. Textbooks do get thicker with each edition, so some topics have to be omitted, but I would not have left out this chapter completely (not only my very personal opinion!).

Many citations help the interested reader to gain more information on the various subjects and most chapters, but not all, are well illustrated.

In conclusion, this is an excellent text book for the experienced clinician or researcher as well as for the young scientist working with or only interested in complement.

Reinhard Würzner, Innsbruck

\begin{tabular}{ll}
\hline KARGER & (1 1999 S. Karger AG, Basel \\
Fax + 4161306 12 34 & 0254-9670/98/0154-0295\$17.50/0 \\
$\begin{array}{l}\text { E-Mail karger@karger.ch } \\
\text { www.karger.com }\end{array}$ & Accessible online at: \\
http://BioMedNet.com/karger
\end{tabular}

